\title{
FRAGMENTO DE LA NACIÓN, GEOGRAFÍA DE DESAFÍO EN LABERINTOS DE ORGULLO, DE ROSA MARÍA BRITTON: UN ESPACIO MUTANTE
}

Humberto López Cruz

\section{(9) $(\mathbb{P Q \Theta \Theta}$}

Doi: https://doi.org/10.15517/rfl.v45i2.39101

URL: https://revistas.ucr.ac.cr/index.php/filyling/index 



\title{
FRAGMENTO DE LA NACIÓN, GEOGRAFÍA DE DESAFÍO EN LABERINTOS DE ORGULLO, DE ROSA MARÍA BRITTON: UN ESPACIO MUTANTE
}

\author{
FRAGMENT OF THE NATION, GEOGRAPHY OF CHALLENGE \\ IN LABERINTOS DE ORGULLO, BY ROSA MARÍA BRITTON: \\ A MUTATING SPACE
}

\author{
Humberto López Cruz
}

\begin{abstract}
RESUMEN
Rosa María Britton ofrece una intrigante especulación narrativa que, desde el siglo veintiuno, reescribe Panamá con ingredientes textuales de una proyección geopolítica afín con el entendimiento que tanto la autora, como la región, deben aceptar como la realidad panameña. Para sustentar estos saberes ha sido necesario que Britton recurra a la historia como zócalo y así cuestionar el paradigma tradicional de la nación; no obstante, es la intención de este ensayo comprender la joven república como espacio privado, llegando a aceptar la región como espacio público y, esta vez como resultado directo, alcanzar una visión más cercana y acertada del ciudadano en ambas representaciones, individual y colectiva. El trabajo se fundamenta en un geocriticismo que indaga los espacios humanos que las artes miméticas organizan por medio de los textos, la imagen y las interacciones culturales relacionadas con ellos. Es el desafío constante de una colectividad fragmentada que responde al llamado de una sola bandera para confrontar un nacionalismo inscrito ya en un siglo republicano e independiente. Dicho de otra forma, la narrativa se verá como una geografía móvil que reclama su lugar; o sea, un espacio que, por medio de un encadenamiento escritural es, y seguirá siendo, mutante.
\end{abstract}

Palabras clave: Rosa María Britton; literatura panameña; espacio; espacialidad; geocriticismo.

\begin{abstract}
Rosa María Britton offers an intriguing narrative speculation that, from the twenty-first century, rewrites Panama with the textual ingredients of a geopolitical projection that fosters the understanding that both the author, as well as the region, must accept as Panamanian reality. In order to sustain this knowledge, it has been necessary for Britton to resort to history as a foundation and thus question the traditional paradigm of the nation; nevertheless, it is the intention of this essay to understand the young republic as a private space, coming to accept the region as a public space, achieving as a direct result a closer and more accurate vision of the citizen in both representations, individual and collective. The article is based on a geocriticism that explores the human spaces that mimetic arts organize through the texts, the image, and the cultural interactions related to them. It is the constant challenge of a fragmented community that responds to the call of a single flag to confront a nationalism already inscribed in a republican and independent century. In other words, the narrative will be seen as a mobile geography that claims its place; it is a space that, by means of a textual chain is, and will continue to be, mutant.
\end{abstract}

Keywords: Rosa María Britton; Panamanian literature; space; spatiality; geocriticism.

Dr. Humberto López Cruz. Profesor del Departamento de Lenguas Modernas. University of Central Florida. Estados Unidos. Correo electrónico: hlopez@ucf.edu

Recepción: 31- 10- 18

Aceptación: 28- 01- 19 


\author{
Las narrativas que afirman \\ el origen republicano de Panamá, \\ forman un conjunto discursivo extenso, \\ plural y diverso que niega, afirma, discute, \\ construye, reinventa y deconstruye, \\ una y otra vez, el origen nacional de Panamá. \\ (Porras, 2009, p. 128). \\ La Historia, es decir el tiempo, pasará, \\ pero quedará siempre la geografía, \\ que es nuestra eternidad. \\ (Cabrera Infante, 1992, p. 15).
}

\title{
1. Introducción
}

El concepto del imaginario se sigue trazando en los mapas intelectuales del continente latinoamericano y, cada vez, las fronteras que lo limitan continúan su inexorable deambular hacia la dilución que confirma un mundo mutante. Si el espacio cambia, las mencionadas fronteras tienen que constituir una demarcación que se adhiera a las exigencias de la nación dentro de la región donde afirma su permanencia; en palabras más simples, tiene que adaptarse a las actualizaciones geográficas o políticas que las diversas necesidades demanden. Un área en constante movimiento no puede sostener demarcaciones limítrofes que se vanaglorien por la rigidez de sus confines; de hecho, se convierte en imposición social auspiciar el concepto de un borde que se transforme, y que se acepte ante tal transformación, las veces que la realidad de la geografía escrutada así lo requiera.

Esta flexibilidad, a la hora de interpretar el mapa, justifica un posible replanteamiento del individuo en función del territorio alterno. Tomando en consideración señalamientos preliminares del estudio de Priscilla Gac-Artigas se entiende que "un cambio en esas relaciones de poder pasa [...] por una modificación en la disposición de los individuos en el espacio social ya que la segregación espacial representa una evidente manera de mantener la segregación de poder" (2017, p. 18). Hay, como es de esperar, otras perspectivas menos evidentes que se escudan tras la cita precedente, amparándose estas en interacciones culturales resultantes de posibles ajustes en los linderos que conforman una nación.

El mapa continúa su mutación, aunque a veces los lectores sospechen que el espacio creado es, en realidad, un espacio imaginado que se va a circunscribir a un sitio inexistente, pero el cual reúne las características precisas para encarnar al individuo y al país en función de una identidad en ciernes y que busca su lugar en el no-lugar de la región. Es decir, es un momento de reflexión designado para obtener un total empoderamiento de las coordenadas, no tan solamente geográficas, sino textuales; la afirmación del ciudadano tiene que situar la lectura en un punto controversial, pero que conlleve a una propuesta de entendimiento, o si fuere ineludible, ante una justificación del espacio en cuestión.

Una vez sentadas las bases requeridas para proseguir, es hora de presentar el área dentro de la región latinoamericana donde se seguirá de cerca un proceso de búsqueda, y a la vez encuentro, con la segmentación de la región. Lo curioso, en este caso, es que se podría establecer una fusión realista entre conceptos que se perfilan disímiles, o sea, aunar ambientes ficcionales y reales. En América Latina, Panamá, en su siempre función ístmica por su historia y posición en el mapa, está logrando una unificación territorial al tiempo que inscribe su 
presencia en una región que tiene que ver esta joven república desde una óptica diferente. Ya no es fragmento de una demarcación colonial ni apéndice de otra nación; sin embargo, es un sitio que sugiere un desplazamiento modificado a la hora de enfrentarlo y, como consecuencia indirecta, cada vez que se vaya, simbólicamente, a efectuar una disección del individuo. La búsqueda de la panameñidad, si se permitiere el término, así lo requiere.

Para que este ensayo se acerque a tal propósito, es menester concluir una lectura que ambicione fomentar un diálogo, y que tal vez sostenga una incipiente perturbación, sobre un volumen de reciente publicación y que abarque la problemática contemporánea del istmo. Al intentar comprender la nación como espacio privado, se puede llegar a aceptar la región como espacio público y, esta vez como resultado directo, alcanzar una visión más cercana y acertada del ciudadano en ambas representaciones, individual y colectiva. Este fin se satisface con una de las entregas más agudas de la narradora panameña, Rosa María Britton (1936-), quien ofrece en su quinta novela ${ }^{1}$ una intrigante especulación ficcional que, desde el siglo veintiuno, reescribe Panamá con ingredientes textuales de una proyección geopolítica afín con el discernimiento que tanto la autora, como la región, deben aceptar como la realidad nacional. Como es de esperar, para sustentar estos saberes ha sido imperioso que Britton recurra a la historia como zócalo y así poner en tela de juicio el paradigma tradicional de la nación ${ }^{2}$. Esto se gestiona por medio de una mirada indagatoria del ya ido siglo veinte y el surgimiento de una república que tendría que hallar sus limitaciones geográficas y sociales en medio de diversas dinámicas de estudio que aspirarían aproximarse a un sitio que muta tras cada escritura.

Tras este preámbulo, es más fácil observar cómo la nación panameña se esfuerza en conformar sus fronteras tras el vaivén político de su primer centenario como república independiente (1903-2003). No es la ocasión de cartografiar las demarcaciones que restringen el país por medio de los puntos cardinales, ni de describir las circunstancias que marcan la geopolítica del momento, sino más bien una internalización: explorar la incisión que no cicatriza; es una que supura, tanto renuncia como cuestionamiento. Nicole Caso arguye que "el servir de puente entre oriente y occidente, y proveerle esta apertura al mundo a costa de la llaga que divide al país por el medio, necesariamente complica para los panameños la respuesta a la pregunta latinoamericana: ¿quiénes somos?” (2007, p. 138). La realidad del canal interoceánico, cual tatuaje vitalicio, es un significante que no cesa de arrojar nuevos significados; la renuncia a un pasado de dependencia deja abierta la interrogante identificatoria que ampara el nacionalismo y que tiene que afirmarse en la región. Britton reúne estos factores inquisitorios para aunarlos en un discurso de permanencia. Laberintos de orgullo se afianza sobre la particularidad de una escritura alterna, no oficial, pero que ofrece la certeza de que Panamá no es un país "inventado". Además, la autora aclara que

1 Britton cuenta en su haber literario con diversas novelas: El ataúd de uso (1983), El Señor de las lluvias y el viento (1988), No pertenezco a este siglo (1992), Todas ibamos a ser reinas (1997), Laberintos de orgullo (2002), Suspiros de fantasmas (2005), Historia de mujeres crueles (2010), Tocino del cielo (2015). La autora también ha entregado cuentos, ensayos y dramas; sin embargo, este trabajo al estar concentrado en un ejemplo de su novelística, solamente las novelas de Britton han sido listadas.

2 En otro trabajo aparte presenté una perspectiva de Laberintos de orgullo a través de una interpretación fundamentada en parámetros históricos. Ahí señalo que el ensayo intenta un análisis de la vertiente histórica y que "la novela presenta un reto para un lector que quiera reconstruir cien años en la vida de una nación y que no tema una lectura a la que quizás se le pudiera tildar de no oficial” (López Cruz, 2003, p. 197). Consúltese el ensayo en su totalidad, la referencia aparece en las obras citadas. 
"la diferencia estriba en el canal, que nos partió en dos mitades que tantos han codiciado" (López Cruz, 2004, p. 376). Y es sobre una supuesta espacialidad en la narrativa que este acercamiento fundamenta su propósito ${ }^{3}$.

A raíz de la firma del tratado Hay-Bunau Varilla en 1903, y tras pocos días de declarada Panamá república independiente, se designó una franja de tierra del país como propiedad, a perpetuidad, de los Estados Unidos ${ }^{4}$. No es el propósito de este ensayo discutir los pormenores del acuerdo bilateral, pero sí subrayar los resultados del mismo que como consecuencia directa marcó el pensamiento de los panameños a través del pasado siglo XX. La llamada Zona del Canal se ha transformado en un espacio fundamental para la acción humana del ciudadano promedio y que, sin su total recuperación, no acepta una satisfactoria asunción de la identidad nacional. Las protestas locales y los variados enfrentamientos con la realidad del istmo jalonaron una gran parte de los acontecimientos que signaron la imposición de un lugar que, a pesar de ser real, para muchos no existía; un área que se veía como el no lugar de la consciencia colectiva. Vega Zúñiga, en su estudio sobre las ampliaciones del canal, concluye su intervención afirmando la importancia que siempre tuvo para los panameños no tan solo el canal sino el rescate de la soberanía en todo el territorio (2017, p. 16). Ahora, se impone enmarcar estos datos histórico-sociales en un emplazamiento geocrítico de Laberintos de orgullo; la institución social de una nación está en el medio.

\section{Un texto que cartografía la nación}

\begin{abstract}
...Pero me contaba de su país de montañas desde donde se miraban dos mares a la vez,

$[\ldots]$

El país que a fuerza de remembranzas permaneció inalterable en su corazón de cristal y es su memoria fresca y que, de cuando en cuando, abría para verlo flotar en un mar de lágrimas.
\end{abstract}

(Nieto, 2008, pp. 13-14).

Como plataforma de este desafío didáctico, es preciso extender un simbólico puente de entendimiento a través del capítulo introductorio de Bertrand Westphal sobre sus teorías

3 Este ensayo enfrenta el canal y la zona aledaña como espacio fundamental para entender la espacialidad textual orquestada por la autora. A pesar de que ahora no se alcanza examinar la narrativa pos-canalera, recomiendo el estudio que ofrece Luis Pulido Ritter y donde concluye que "no se puede dejar de afirmar que en el país de la utopía triunfante, donde la lucha por la recuperación del Canal había servido de unificador imaginario de la nación, la posnovela canalera recrea -a posteriori- las viejas exclusiones que son reproducidas en las construcciones textuales" (2012, p. 92). Hay posturas muy sugerentes que servirían para una continuación de este ensayo y que no deben ser desestimadas. No serán comentadas por apartarse del eje central ahora presentado, pero los lectores interesados podrán consultar, si así quisieren, la palabra de Pulido Ritter.

4 El tratado firmado por el Secretario de Estado norteamericano, John M. Hay, y el representante de Panamá, Philippe Bunau-Varilla, fue el que determinó la imposición, o aceptación, del espacio de la zona para la construcción del canal interoceánico así como el gobierno y administración del mismo. Los lectores sabrán que, en 1977, se firmó el tratado Torrijos-Carter determinando que con el amanecer del 1 de enero de 2000, las operaciones canaleras serían revertidas, en su totalidad, al gobierno panameño. Hay una cantidad considerable de textos que intentan arrojar luz a estos entramados internacionales, los interesados podrán acercarse a la versión que mejor concuerde con sus convicciones sobre el tema. 
relacionadas con los reductos real y ficcional. Este señala que "el geocriticismo explora los espacios humanos que las artes miméticas organizan a través de, y en, los textos, la imagen y las interacciones culturales relacionadas con ellos" (2011, p. 6, la traducción es mía). Aquí puede resumirse la esencia de la novela de Britton: es la imagen de una nación emergente que se va a afirmar por medio de una escritura que observa a su derredor y, a su vez, se deja observar por una región que tiene que aceptar la nueva república como parte de sí; de otra manera, el espacio mutado no abarcaría, ni incluiría, la totalidad de su entorno. El protagonista ${ }^{5}$, en función de la sociedad que representa, reflexiona: "tengo que rebuscar en el pasado la clave para enterrar los fantasmas que me persiguen y atormentan” (Britton, 2002, p. 70); no obstante, lo peculiar de la escena es que el individuo intenta regresar al que considera su pueblo natal, un sitio imaginario creado por la autora para desarrollar sus ficciones, un no-lugar dentro de los límites de Panamá que va a asumir, a mimetizar, el espacio real de una región en evolución 6 . Obsérvese que a medida que el protagonista rememora su pasado, su pueblo, "donde cualquier suceso era excusa para el pecado" (Britton, 2002, p. 49), va quedando atrás para dar vida a la ciudad de Panamá; la comparación es indefectible para que el tiempo avance y se modifiquen algunos de los puntos donde se estacionan las coordenadas discutidas.

La ambientación forma parte de la interacción con las diversas facetas que unifican el simbólico puente que se ha creado entre híbridos puntos de la expansión nacional. Así se va a convergir en un núcleo más cerrado, pese a la apertura que pudiera desprenderse del concepto capitalino, ya que la ciudad, la capital, se impondrá al personaje. Su primer eslabón en el proceso mutante indica que "quedé como alelado mirando los carros, los edificios de varios pisos que nunca había visto. La gente era distinta [...]. Me daba la impresión de haber muerto y resucitado en otro planeta. [...] Todo, todo era diferente, otro mundo" (Britton, 2002, pp. 90-91). El individuo, investido con una función protagónica, experimentará un desarrollo humano que oscilaría entre una geografía imaginaria y una real. El lector promedio no se percatará de la metamorfosis escenográfica urdida por Britton, pero sí comprobará que la nación, o la imagen de ella, ha cambiado para ofrecer una visión más contemporánea y global sin perder una parte del atributo colectivo que insiste, e insistirá, en formar parte de la región que le pertenece.

Regresando a Westphal, el erudito francés sugiere que a comienzos del siglo pasado pudo existir un arreglo entre tiempo y espacio (2011, p. 26). Esto es fundamental puesto que el concepto se enmarca con la emancipación de Panamá y su nacimiento como república independiente. En otras palabras, en los momentos en que se pudiera percibir una posible tregua entre la geografía y la historia, el mundo es testigo de la afirmación nacionalista de un país y, como trascendencia literaria, Britton decide apuntalar el comienzo desde donde narrar su país. En este caso, y a pesar de perseguir esta propuesta una aproximación geocrítica, es

$5 \quad$ He decidido, a propósito, omitir el nombre del protagonista de todo este ensayo crítico. No me interesa que el análisis se enfoque en la realidad inventada de un individuo en particular, sino en la geografía que representa. Pese a ello, en un intento de satisfacer a lectores curiosos, aclaro que Britton ha llamado a su personaje protagónico, y sobre el cual descansa la intensidad de la narrativa, Santos Calderón.

6 Me refiero al espacio ficticio de Chumico. Este es el mismo pueblo donde se fundamenta la trama de la primera novela de Britton, El ataúd de uso (1983). Hay vagas alusiones en Laberintos de orgullo que no pasarán inadvertidas para los lectores que estén familiarizados con la novelística de la autora panameña, ya que el texto apunta al patriarca que, en otra época, fundara y poblara el lugar. Lee A. Daniel ha observado que "el resultado es, y no importa a cual grupo pertenece el pueblo, que suele ser realista, típico y semejante a todas las comunidades salpicadas por las Américas” (2003, p. 64). Recomiendo la lectura del artículo de Daniel. 
necesaria la incorporación de parámetros históricos que contribuyan a emplazar el lugar; o sea, que deje de ser un territorio incierto, como lo es el sitio del nacimiento del protagonista y así afianzarse en la presencia dialéctica de dicho lugar: el centro que desplaza la periferia. Britton no aclara la nacionalidad de su personaje ya que su madre, colombiana, lo "parió solita en medio de la selva antes de tiempo, cuando iba por el trillo que hacen lo madereros huyendo de su pasado, sin saber si estaba en Panamá o en Colombia" (Britton, 2002, p. 52). En realidad, no hace falta destruir el simbolismo presente al separar a la madre de su hijo y, teniendo en cuenta que la cartografía local auspicia la presencia de la historia para sustentar un espacio flotante y mitigar el posible dolor emocional que fuera para muchos la separación del istmo de la Gran Colombia, la inclusión de los términos pareciera estar, si no justificada, al menos aceptada: Colombia, en toda su imposición, siempre será parte de la historia de Panamá. Por otro lado, y más adelante en la narrativa, el individuo admite que le fue bastante difícil, después del golpe de estado en el istmo, regresar a un país ocupado por militares (Britton, 2002, p. 205). Una vez más, superada las diferencias entre los términos precedentes, la colaboración entre ambos, historia y geografía, parece encontrar un punto medio donde asentar un enunciado fragmentado encaminado a colocar en el mapa lo que hasta entonces rotaba alrededor de ejes imaginarios.

Este compromiso del discurso hallaría una satisfactoria intersección en un reducto común que probaría la creación, o aceptación de algo ya existente, de un conjunto que compartiera atributos históricos y geográficos que no pudieran desasociarse de la esencia del lugar. El argumento tendría que adaptarse para satisfacer los puntos precedentes y así conformar una trama que se afianzare en su movilidad; es decir, cada aportación de Britton, cada aserto de la novela, es una pieza que contribuiría a un eficaz acercamiento entre el individuo y el espacio en el que tiene que desenvolverse para validarlo. Convendría, pues, repasar la visión que presenta, del término, Michel de Certeau cuando apunta que

El espacio es un cruzamiento de movilidades. Está de alguna manera animado por el conjunto de movimientos que ahí
se despliegan. Espacio es el efecto producido por las operaciones que lo orientan, lo circunstancian, lo temporalizan
y lo llevan a funcionar como una unidad polivalente de programas conflictuales o de proximidades contractuales.
El espacio es al lugar lo que se vuelve la palabra al ser articulada, es decir cuando queda atrapado en la ambigüiedad
de una realización, transformado en un término pertinente de múltiples convenciones, planteado como el acto de un
presente (o de un tiempo), y modificado por las transformaciones debidas a contigüidades sucesivas (2013, p. 129).

Formulado de otra manera, la imagen real del espacio sustenta el desarrollo de un mundo ficcional que apela a la geocrítica para ubicar, si los lectores necesitaren esta infundida asistencia, una narrativa que se fundamenta en su historia sin abandonar la geografía; mientras más se adentran los hilos en la madeja discursiva de la trama, más se entrelazan los conceptos expuestos sin que el definido espacio pueda dirimir la contienda y establecer una clara separación entre ambos. Son aristas de una misma figura que va cobrando forma, van transformándose, pese a lo aleatorio de su plataforma argumental. Hay que pausar, regresar al texto y recordar que el protagonista proviene de un lugar fronterizo incierto, de un sitio imaginario del que ni el propio individuo tiene consciencia; además, el poblado de Chumico, aceptado por el narratario como auténtico, es producto de la imaginación autorial y no un lugar delineado en el mapa. Esto contribuye a la articulación del no-lugar y, desde que el personaje acepta su realidad ficcional, solidifica su aura de incertidumbre: "era la primera vez que en forma tan directa aceptaba sus orígenes y sintió una especie de alivio: había recuperado en parte su identidad" (Britton, 2002, p. 264). El hecho de que recupera en parte su identidad es debatible porque, en representación de toda una nación, está recobrando una alegada 
fusión reconocible con una ubicación imaginada; o sea, el individuo promedio no tiene aún, de acuerdo al relato de Britton, una conexión sólida con la totalidad de su geografía. Las coordenadas de la Zona del Canal, ajenas al colectivo nacional, siguen modificando la historia y los lectores saben que será el factor determinante en Laberintos de orgullo que contribuya con la identificación, y aceptación, de la sociedad panameña.

Los mecanismos de funcionamiento circunstancian los espacios, pero, para el lector, tardan en temporalizarlos ya que lo transitorio, a pesar de constituir tan solamente un siglo de historia, abarca la longitud total de la novela. Desde

en la escuela les habían señalado que existía por tratado una zona alrededor del Canal para su protección y que los americanos vivían allí, pero nadie en Chumico le había contado el resto o, a lo mejor, no se habían enterado de la situación (Britton, 2002, p. 96).

para proseguir con "es una situación muy compleja, pero creo que ha llegado la hora de cortar el cordón umbilical que nos une a los Estados Unidos. Es lo justo, son muchas las humillaciones que hemos soportado [...], hay mucho resentimiento" (Britton, 2002, p. 267), hasta culminar en el preludio del futuro traspaso de la administración a manos nacionales puesto que "la gran mayoría de entusiastas panameños que había votado a favor de los tratados, no se enteró de las enmiendas añadidas cuando finalmente fue aprobado por el senado norteamericano" para ampliar que "estas pasaron desapercibidas por el público en general, que a lo único que aspiraba era a la retirada de las tropas americanas del istmo para recuperar la soberanía de una vez por todas" (Britton, 2002, p. 307) ${ }^{7}$. El haber engarzado este desarrollo narrativo apuntala espacios mutantes que van a afirmar su autenticidad, aunque aparente incongruencia, en la ambigüedad que ha de experimentar la nación fragmentada en la búsqueda de su totalidad. Es aconsejable constatar la referida fragmentación, ya que el uso pronominal de la escritura recodifica el significado; el les de los múltiples estudiantes varía y se reduce al le con que le tienen que contar la verdad al protagonista -representando una identidad en aprietos-, o lo que pudiera aceptarse como verídico dentro de una geografía politizada, en circunstancias que van cimentando las diversas movilidades con las que Britton refuerza su novela.

De este modo y de principio a fin, Laberintos de orgullo es un notable esfuerzo literario por agrupar los verbos que aparecen en infinitivo en el epígrafe de María Elena Porras, que encabeza este ensayo, para exponerlos y desarrollarlos como parte de un relato devoto al ofrecimiento de una toma de consciencia del espacio subrayado. Panamá se ciñe, por momentos, a una franja de tierra - la más controvertida de la república- conocida como la Zona del Canal. Certeau ve su propuesta realizada al articularse la palabra en la realización de una idea, un concepto: la afirmación nacional que necesitará la totalidad de la unión del suelo patrio bajo el mismo pendón y como respuesta a transformaciones variadas, una parte de

$7 \quad$ Aquí el texto hace referencia a la invasión estadounidense a Panamá, en 1989 y bajo la presidencia de George H. W. Bush, denominada Just Cause por el gobierno de Estados Unidos. Hay muchas publicaciones que hablan de la invasión desde diversas plataformas de entendimiento; los lectores deben escoger la orientación que consideren más acorde a sus ideas. Sin interés de desembocar en un debate político, suelo recomendar el informe de una comisión independiente (Independent Commission of Inquire on the U.S. Invasion of Panama, 1991) que realizó una investigación sobre este hecho bélico y, además, el artículo de Malcolm McConnell (1991); hay mención a ambas en las obras citadas. Pese a ello, me interesa citar algo que Britton apunta en su novela cuando fustiga a un determinado sector social: "quizás si los poderosos hubieran dado la cara a tiempo, no habíamos tenido que sufrir el trauma de la invasión" (2002, p. 277). Esto puede sugerir la postura de la autora. 
las modificaciones irrevocables, que dicho espacio deberá sufrir. La Zona no puede constituir una excepción; de hecho, es el epicentro del propósito de la colectividad ciudadana y desde donde se impulsará un intento vectorial dirigido a consolidar la afirmación, que mediante la espacialidad discursiva, logrará la nación.

\section{La afirmación del espacio nacional}

\section{El concepto básico de la narratología no es la "historia", sino el "mundo narrativo" definido dentro de una tipología de mundos posibles. \\ (Doležel, 1999, p. 57).}

Esta primera parte conlleva a presentar una obligatoria fusión enunciativa donde la geografía estudiada permita a la historia acercarse para dar forma a un discurso literario que, de otra forma, no se hubiera desarrollado a plenitud. Es un matrimonio a conveniencia que triunfa porque los dos términos se benefician de la unión; al mismo tiempo, ambos mantienen sus características propias permitiendo un desenvolvimiento de lecturas abiertas que sustenten sus propios intereses colaborando, a veces, con la postura del otro. El espacio mutante va a evolucionar una vez más puesto que la práctica de la espacialidad requiere otorgar un matiz de realidad a una voz que continúa auxiliándose de la historia. Con respecto a la Zona del Canal, área que sigue suplantando la totalidad de la territorialidad ístmica, el poder dictatorial se reta intentando anular el acuerdo que unificaría el territorio panameño bajo una misma bandera: "las falsas acusaciones en su contra tenían como motivación evadir el compromiso de regresar el canal en el año dos mil, como estaba estipulado en los tratados" (Britton, 2002, p. 508), marca un momento decisivo de cómo, en poco tiempo, se modificaría el mapa del país ${ }^{8}$.

Robert T. Tally, siguiendo una rica trayectoria de estudios sobre la espacialidad, subraya que el análisis de las prácticas espaciales y de los espacios históricos permiten reconocer el grado al que textos literarios operan y ayudan a formar la geografía de sus mundos, y a través de ellos, el nuestro (2013, p. 99). Britton ha sabido manipular el concepto remarcado añadiendo un toque de malicia escritural, puesto que los lectores ya son conscientes del desenlace; en otras palabras, la geografía -entiéndase geopolítica- está en proceso de formación textual, pero el mundo que se debería formar tras los postulados de la autora ya, hace tiempo, está instituido. El factor sorpresa ha desaparecido, la historiografía se ha encargado de facilitar los conocimientos; sin embargo, esto no es óbice para que se altere, o falsifique, la postura de Tally.

¿Por qué Laberintos de orgullo se adhiere a un proceso de desmontaje que juega con la historia concentrándose, más bien, en la búsqueda de una geografía idílica? Pues, sencillamente, porque son lecturas yuxtapuestas donde, a pesar de la validez e importancia del tiempo, no vacilan en repetir la problemática social cuando enfrentan el controversial tema de la unificación nacional. Ronald Spiller manifiesta que "la literatura como medio de

8 Los lectores saben que estas acusaciones textuales iban dirigidas a Manuel Antonio Noriega quien, en esos momentos, gobernaba Panamá. La Zona del Canal, y su importancia en la arena internacional, motivaba a la potencia extranjera a ejecutar la conocida invasión al istmo. Revísese la nota anterior que habla de la operación Just Cause. 
la memoria forma parte de los decursos que participan en la memoria colectiva" (2011, p. 202). En la novela, Britton admite la importancia que ha tenido para todos los panameños el siempre citado canal y la zona colindante. La preocupación colectiva ha dejado de observar la historia para concentrarse en la geografía del istmo: la ausencia extranjera conlleva, sin lugar a dudas, a una unificación geográfica y, como alegato adicional, a lograr la aceptación del lugar tangible. El no-lugar debe ir desvaneciéndose en un pasado al que la nación no va a regresar. La autora no es escueta al apuntar que la "historia es lo que es y no podemos cambiarla, pero qué fácilmente olvidamos, qué fácil es manipular el pasado y hacerlo aparecer con otras luces y reflejos engañosos" (López Cruz, 2002, p. 29) ${ }^{9}$. Este supuesto olvido podría encontrar eco en la rapidez con que el colectivo acepta una nueva propuesta con el fin de alterar la geografía involucrada, desdeñando la historia como factor de obligada consulta al momento de circunstanciar el presente y así ambicionar cimentar el futuro. Paradójicamente, y aquí la revelación textual podría resultar confusa, mientras que con anterioridad se vislumbraba el arribo al lugar so pena de desaparecer el no-lugar ideado, ahora permite que, tras la posibilidad de un olvido plural, el referido no-lugar se instale con mayor intensidad en una escritura que, a pesar de no ser notoria por tergiversar la historia, no es optimista al augurar el destino de la joven república. Ambos, Panamá y personaje, enfrentan un futuro incierto, eso sí, en una geografía mutada. La voz narrativa sostiene que "me interesa demasiado conocer la historia que no acabó de contarme; necesito ser parte del resto de esa vida, de los días, por muy poco que sean [...] ahora, todo es cuestión de tiempo" (Britton, 2002, p. 546); aquí no se observa al individuo desde la óptica propia sino de la nación ${ }^{10}$. De acuerdo a Britton, es cuestión de tiempo ver a un Panamá reunificado que, como dato curioso, va a ser escudriñado desde el exterior al estar la narradora y el protagonista, doctora y paciente, en los Estados Unidos. Los ya vistos textos yuxtapuestos pueden manipular la historia, pero no la geografía. Esto sería un triunfo trascendente para la geocrítica: la simultaneidad de espacios ha ofrecido otro alcance de entendimiento, y lectura alterna, a una novela de un distintivo rasgo nacionalista que logra lúcidas intersecciones con una certera proyección de la espacialidad del istmo.

Ahora bien, tales desmontajes achacados a la trama de Britton dispensan parámetros discursivos donde el tiempo, pese a proyectarse cronológicamente en Laberintos, es recibido y aceptado a la vez por el lector; un siglo de historia comprimido en la reminiscencia del protagonista. Esto justificaría una acepción al término de la fragmentación temporal, imprescindible en su totalidad, al otorgar a la memoria individual un rasgo preponderante en la redefinición concerniente a las coordenadas analizadas. Además facilitaría, sin proponérselo,

9 Esta entrevista forma parte de un libro editado con motivo del primer centenario de Panamá como república en el que Britton (López Cruz, 2002, pp. 15-63) comparte su contenido con dos figuras literarias panameñas: Ramón Fonseca Mora (López Cruz, 2002, pp. 65-116) y Ricardo Arturo Ríos Torres (López Cruz, 2002, pp. 117-144). La ficha completa se halla en las obras citadas. El detalle aludido ha aparecido en otros de mis estudios sobre la narrativa de Britton por estimar substancial la forma en que la autora enfrenta la historia y cómo la proyecta en sus textos.

10 En otra entrevista, Britton acepta que Panamá se ve reflejada como república en el final de la novela; además, indica que "el lector puede imaginar el final que le parezca" (López Cruz, 2004, p. 375), agregando que muchos lectores le reclamaron, en sus días, un final feliz (López Cruz, 2004, p. 375). Lo relevante de la respuesta es que la novelista establece una separación entre la nación y el protagonista ampliando, de esta forma, el factor de espacialidad visto durante toda la narrativa. 
la aceptación del entramado textual; la espacialidad tendría que asumir el recuerdo del personaje como desplazamiento de la construcción testimonial. Esto es, el siempre socorrido espacio, aunque no fuere común, ha de incluir todas y cada una de las facetas de la memoria, del aludido recuerdo, como articulación espacial; pasado y presente se juntan transformados en múltiples convenciones que conocen, al igual que los lectores, el futuro.

Junto con esta visión, cabría examinar que "conceptualizar un evento o cosa como un lugar en el espacio implica considerar todo lo que rodea y define sus atributos o sistemas" (Izquierdo, 2012, p. 133). Esta presunción, aceptada como válida, privilegia la escritura dentro de los mundos posibles de desenvolvimiento argumental; se podría colegir que en Laberintos mirar hacia atrás es mirar hacia el futuro. El país, ya afianzado en su centenario como república independiente, está forjándose en los recuerdos. La viabilidad de los mundos narrativos favorecida por Doležel en el epígrafe de esta sección se cumple a cabalidad en una novela que conoce de antemano a donde conducir al lector. Regresando al crítico checo, "la semántica de la ficción consiste en una fusión de significados extensionales e intencionales" (Doležel, 1999, p. 63). Britton se apropia de estos significados para, no solo suplantar un discurso que debe afirmarse en su flexibilidad, sino también para modificar los puntos de mira con que se percibirá la Zona, entiéndase la nación, desde el lugar en que se fragua.

\section{Una geografía en mutación}

Space often elicits modification.

(Harvey, 2006, p. 119)

La autora no oculta que el espacio suscita modificaciones y la estructura de Laberintos no se resiste ante tal estipulación; de hecho, parece colaborar implícitamente con una ubicación textual que tiene que estar presente en su expansión y, acertadamente, en la modificación aducida. La Zona ha de atravesar la metamorfosis esperada para, no solo ser vista desde diversas posibilidades, sino probar que es una demarcación renovada o, valga la redundancia, un espacio mutado.

La autoridad geográfica concurrirá con precisión al auxilio del texto; la posición privilegiada del istmo solventa, al instante, cualquier duda posible. Britton los asume porque

Panamá, un lugar de paso obligatorio desde el inicio del descubrimiento. Los ojos de las grandes potencias estaban fijos en nuestra estrecha cintura. Primero fue el ferrocarril, después el Canal Francés y su gran fracaso y por último el esfuerzo norteamericano que culminó en la construcción del canal (López Cruz, 2004, p. 366).

El área remarcada se contrapone con el pasaje de Laberintos que reza que mientras el presidente

se pasa la mayor parte del tiempo en fiestas con visitantes importantes [...] o correteando entre un continente y otro para obtener apoyo para los proyectados tratados sobre el Canal, el país está manejado por unos cuantos que han permitido toda esta corrupción que nos agobia (Britton, 2002, p. 275).

El control hace que el poder oscile dentro de la demarcación que sigue resistiendo embates internos y externos; sin embargo, sus ya obsoletas fronteras no pueden sostener lo que la historia determinó imposible y comienzan a quebrantarse. No obstante, ¿es este el fin de una geografía comprometida con un ideal ya satisfecho? Muy por el contrario: la Zona, en su 
ampliación física tras celebrado el primer centenario, continúa redefiniéndose y reinventándose para así no perder su relevancia en la región ${ }^{11}$.

En realidad, lo que el lector observa es la evolución de una conceptualización de atributos que comenzó antes que Vasco Núñez de Balboa atravesara el territorio ístmico y arribara a lo que nombró Mar del Sur ${ }^{12}$. Esto fuerza regresar a Harvey cuando concluye que obtener un sentido de cómo es el espacio y cómo funcionan las diversas espacialidades y espacio-temporalidades es crucial para la construcción de una imaginación distintivamente geográfica; y al mismo tiempo, incorpora la preocupación de que el expresado espacio resulta ser una palabra clave extraordinariamente complicada (2006, p. 148). La supuesta complicación del término no toma en consideración la atemporalidad de la Zona del Canal como sitio emblemático de los propósitos de una nación; no es tan solamente la culminación de un siglo en pugna, sino los pilares para nuevos derroteros que serán modificados, sin lugar a dudas, por subsiguientes contigüidades. Britton parece sugerir una prolongación en la espacialidad textual que no va a mermar en un futuro inmediato, aunque esta vez los lectores no posean las claves de continuidad con las que contaron durante su experiencia con Laberintos. Es el desafío constante de una colectividad que responde al llamado de una sola bandera; un reto al nacionalismo inscrito ya en un siglo republicano e independiente. En palabras más teóricas, una geografía móvil que reclama su lugar; acéptese un espacio que, por medio de un encadenamiento escritural, es y seguirá siendo, mutante.

\section{Bibliografía}

Britton, R. M. (2002). Laberintos de orgullo. Santafé de Bogotá: Santillana.

Cabrera Infante, G. (1992). Mea Cuba. Barcelona: Plaza \& Janes.

Caso, N. (2007). Laberintos de apariencias y reiteraciones: reconstruyendo la integridad psíquica/nacional en Laberintos de orgullo de Rosa María Britton. En H. López Cruz (Ed.). Rosa María Britton ante la crítica (pp. 130-148). Madrid: Verbum.

Certeau, M. de (2013). La invención de lo cotidiano. I. Artes de hacer. En A. Pescador (Trad.) y L. Giard (Ed.). México: Universidad Iberoamericana.

Daniel, L. A. (2003). Explorando nuevos espacios: los pueblos imaginarios de Rosa María

11 En 2006 comenzó, o al menos se aprobó, un proyecto para la ampliación del canal. Vega Zúñiga agrega que una vez aceptado "lo importante que ha sido a través de la historia la construcción y uso del Canal de Panamá, y ahora de manera superlativa lo que representa su ampliación, surge en nosotros la siguiente interrogante: ¿cómo este patrimonio revierte a los panameños?” (2017, p. 14). Esta encrucijada, planteada en el presente, augura que el espacio no perderá el aura de constante desafío que lo caracteriza y, aunque fuera de las páginas de la novela de Britton, predice futuras modificaciones en unas coordenadas geográficas que no se sorprenderán ante la continuación de una metamorfosis esperada.

12 Los lectores recordarán que Britton comienza su novela inspirada en el viaje que realizó a Panamá el rey belga Leopoldo III en la década de los 50s. El plan del rey era seguir los pasos de Núñez de Balboa en su travesía ístmica. La autora aclara en su "Breve explicación histórica a manera de prólogo" (2002, pp. 9-12) que "me pareció interesante retomar el viaje de suroeste a nordeste, como lo hizo Balboa de vuelta a Santa María La Antigua, insertar protagonistas y pueblos ficticios; en fin, novelar a mi manera la gran aventura del rey Leopoldo III de Bélgica" (2002, p. 11). El viaje de Britton conduce su narrativa a través de un espacio cambiante; subrayo: no puede ser estático. 
Britton. En H. López Cruz (Ed.). Encuentro con la literatura panameña (pp. 61-80). Panamá: Círculo de Lectura de la USMA.

Doležel, L. (1999). Heterocósmica. Ficción y mundos posibles. F. Rodríguez (Trad.). Madrid: Arco/Libros.

Gac-Artigas, P. (2017). Espacio urbano e identidad: el rol de la transgresión del contexto emotivo asociado a la geografía en la construcción de la identidad. Glosas, 9(3), 17-24.

Harvey, D. (2006). Spaces of Global Capitalism. London; New York: Verso.

Independent Commission of Inquire on the U.S. Invasion of Panama. (1991). The U.S. Invasion of Panama. The Truth Behind Operation 'Just Cause'. Boston: South End.

Izquierdo, L. (2012). Espacio y lenguaje: una cartografía de Chimbote en El zorro de arriba y el zorro de debajo de José María Arguedas. Revista de Crítica Literaria Latinoamericana, 38(75), 131-148.

López Cruz, H. (2002). Asedio a Panamá: su literatura. Panamá: Círculo de Cultura de la USMA.

López Cruz, H. (2003). Laberintos de orgullo de Rosa María Britton: (re)escribiendo la historia panameña. Monographic Review, 19, 196-208.

López Cruz, H. (2004). La historia panameña revisada: Rosa María Britton. En L. Alonso Gallo (Ed.) Voces de América/American Voices (pp. 363-379). Cádiz: Aduana Vieja.

McConnell, M. (1991). Just cause. The Real Story of America's High-Tech Invasion of Panama. New York: St. Martin's Press.

Nieto, M. O. (2008). Ardor en la memoria. Panamá: La Rama Dorada.

Porras, A. E. (2009). Cultura de la interoceanidad. Narrativas de identidad nacional (19902002). Panamá: Universidad de Panamá.

Pulido Ritter, L. (2012). 'Los de abajo' en el país de la ‘utopía triunfante'. Aproximación a la novela poscanalera 2001-2011. Centroamericana, 22(1-2), 75-93.

Spiller, R. (2011). 'La verdad de la memoria en la memoria de la verdad'. Poiesis después de Auschwitz: Juan Gelman. En J. Reinstädler (Ed.). Escribir después de la dictadura. La producción literaria y cultural en las posdictaduras de Europa e Hispanoamérica (pp. 197-220). Madrid y Frankfurt: Iberoamericana/Vervuert.

Tally, Jr. R. T. (2013). Spatiality. Londres y New York: Routledge.

Vega Zúñiga, M. G. (2017). El Canal de Panamá: un enfoque sobre su importancia económica a través de nuestra historia. Lotería, 534, 6-16.

Westphal, B. (2011). Geocriticism. Real and Fictional Spaces. R. T. Tally, Jr. (Trad.). New York: Palgrave. 